Review Article

\title{
Moxibustion for the Correction of Nonvertex Presentation: A Systematic Review and Meta-Analysis of Randomized Controlled Trials
}

\author{
Qin-hong Zhang, ${ }^{1}$ Jin-huan Yue, ${ }^{1,2}$ Ming Liu, ${ }^{3}$ Zhong-ren Sun, ${ }^{1,2}$ Qi Sun, ${ }^{1,2}$ \\ Chao Han, ${ }^{1,2}$ and Di Wang ${ }^{1,2}$ \\ ${ }^{1}$ Department of Acupuncture and Moxibustion, College of Acupuncture and Moxibustion, Heilongjiang University of Chinese Medicine, \\ Harbin 150040, China \\ ${ }^{2}$ The Second Affiliated Hospital, Heilongjiang University of Chinese Medicine, Harbin 150040, China \\ ${ }^{3}$ College of Basic Medical Sciences, Heilongjiang University of Chinese Medicine, Harbin 150040, China
}

Correspondence should be addressed to Zhong-ren Sun; sunzhongren2011@163.com

Received 29 March 2013; Revised 18 June 2013; Accepted 31 July 2013

Academic Editor: Lixing Lao

Copyright (C) 2013 Qin-hong Zhang et al. This is an open access article distributed under the Creative Commons Attribution License, which permits unrestricted use, distribution, and reproduction in any medium, provided the original work is properly cited.

Objectives. This study aims to assess the effectiveness and safety of moxibustion for the correction of nonvertex presentation. Methods. Records without language restrictions were searched up to February 2013 for randomized controlled trials (RCTs) comparing moxibustion with other therapies in women with a singleton nonvertex presentation. Cochrane risk of bias criteria were used to assess the methodological quality of the trials. Results. Seven of 392 potentially relevant studies met the inclusion criteria. When moxibustion was compared with other interventions, a meta-analysis revealed a significant difference in favor of moxibustion on the correction of nonvertex presentation at delivery (risk ratio (RR) 1.29, 95\% confidence interval (CI) 1.12 to 1.49 , and $I^{2}=0$ ). The same findings applied to the cephalic presentation after cessation of treatment (RR 1.36, 95\% CI 1.08 to 1.71 , and $\left.I^{2}=80 \%\right)$. A subgroup analysis that excluded two trials with a high risk of bias also indicated favorable effects (RR $1.63,95 \%$ CI 1.42 to 1.86 , and $\left.I^{2}=0 \%\right)$. With respect to safety, moxibustion resulted in decreased use of oxytocin. Conclusion. Our systematic review and meta-analysis suggested that moxibustion may be an effective treatment for the correction of nonvertex presentation. Moreover, moxibustion might reduce the need for oxytocin.

\section{Introduction}

Moxibustion is a traditional Chinese medical intervention that utilizes the heat generated by burning herbal preparations containing Artemisia vulgaris (mugwort) to stimulate acupuncture points [1]. It is also believed to be effective in the treatment of stroke rehabilitation [2], pain [3], cancer care [4], ulcerative colitis [5], hypertension [6], osteoarthritis [7], constipation [8], child chronic cough [9], and breech presentation [10]. In China, moxibustion on the Zhiyin (BL67) point, located on the outer corner of the fifth toenail, has long been used to correct nonvertex presentation in obstetrics [11, 12]. Possible mechanisms of action attributed to moxibustion include stimulation of the production of placental oestrogens, alterations in prostaglandin levels, and promotion of the uterine contractility, which leads to a stimulation of fetal movements and a higher probability of vertex presentation of the fetus $[10,12-14]$.

Before moxibustion can be recommended for routine clinical use for the correction of non-vertex presentation, evidence from randomized controlled trials is required. Unfortunately, most studies in which the moxibustion has been evaluated are open clinical trials, blinded to neither the practitioner nor the subjects. In moxibustion trials, sham treatments are conducted by adding insulation below the moxa pillar to prevent the transfer of heat from the pillar to the patient [15]. The sham treatment looks similar to the real moxibustion treatment in appearance and burning 
procedure, and participants are able to smell the smoke or observe the burning moxa [15].

The efficacy of moxibustion for the correction non-vertex presentation has been evaluated in four clinical reviews [2326]. All four studies failed to include all of the relevant articles published [23-26]. For example, none of these reviews included the study of Yang and colleagues [16], which met all of the inclusion criteria for each of the four reviews. Additionally, all of these reviews included interventions other than moxibustion including acupuncture [23-26]. Finally, some reviews included controlled clinical trials [23] and quasirandomised controlled trials [24-26] which were poorly executed and might have affected the conclusion of the reviews.

The objective of the current review and meta-analysis was to perform a comprehensive literature search to find and evaluate high-quality RCTs. Also, our study aim was to critically evaluate the clinical efficacy and safety of moxibustion therapy alone for the correction of non-vertex presentation (not combined with acupuncture or acupuncture alone).

\section{Materials and Methods}

2.1. Literature Search. The comprehensive literature search included the following electronic databases: MEDLINE (1950 to February 2013), EMBASE (1980 to February 2013), Cochrane Library (1980 to February 2013), CINAHL (1982 to February 2013), AMED (1985 to February 2013), British Nursing Index (1993 to February 2013), Chinese Biomedical Literature Database (CBM; 1980 to February 2013), China National Knowledge Infrastructure (which includes the database China Academic Journals) (CNKI; 1980 to February 2013), VIP Information (VIP; 1980 to February 2013), Wanfang Data (WAN FANG; 1980 to February 2013), Science paper Online (2006 to February 2013), and 28 major Chinese traditional medicine journals.

The following search terms were used: moxibustion OR moxa AND non-vertex presentation or labor presentation or abnormal foetal position or abnormal foetal presentation or podalic presentation or complementary medicine or alternative medicine. We also performed a hand search to identify any other articles. In an attempt to minimize the omission of potentially relevant trials, we also reviewed the reference lists of included articles and relevant reviews for additional eligible studies. Both published and unpublished studies were considered. No language restrictions were imposed.

2.2. Selection of Studies. Potentially relevant studies were independently evaluated by two reviewers (Y. J. H. and Z. Q. H.). Reviewers screened all titles and abstracts when available and they examined the full text if the study met the following inclusion criteria: (a) was a RCT; (b) included a comparison of moxibustion with nonmoxibustion therapy; and (c) included no restriction on the race or gestation of participants with a singleton non-vertex presentation. However, the study with following criteria was excluded: (a) duplication; (b) complex therapy that could not figure out the effect of moxibustion for example, treatment group used moxibustion plus Chinese herbal ointment, while the control group used knee-chest therapy; (c) incomplete data (failed to provide basic characteristics of participants, such as age, gestational week, and duration of intervention); and (d) wrong intervention or comparator that could not evaluate the effect of moxibustion; for example, treatment group used moxibustion plus acupuncture intervention, while control group used moxibustion intervention. Disagreements between the two reviewers were resolved by discussion with a third author (S. Z. R.) to achieve consensus.

2.3. Outcome Measures. In this review, we present the results for the cephalic presentation at birth and after cessation of treatment. In addition, use of oxytocin, Apgar scores less than 7 at 5 minutes, cesarean section, preterm delivery, premature rupture of membranes, intrauterine fetal death, placental abruption, and cord blood $\mathrm{pH}$ less than 7.1 were also recorded.

2.4. Data Extraction. Two authors (S. Q. and H. C.) independently extracted data from eligible studies using a predesigned extraction sheet and a third author (W. D.) verified the extracted data. Any discrepancies were settled through discussion. The third review author (W. D.) was consulted if a consensus could not be reached. The extracted data included demographic data, clinical characteristics of the study groups, quality of trial design, inclusion and exclusion criteria, interventions, results, and adverse events. If the required information was not available in the included studies, we contacted the original authors by email.

2.5. Quality of the Studies. The Cochrane risk of bias tool [27] was used to assess methodological quality of the trials. Two authors (Y. J. H. and Z. Q. H.) were independently involved in quality assessment. All discrepancies were resolved by consensus with the other author (L. M.).

2.6. Statistical Analysis. Data were pooled using the randomeffects model. Treatment effect was expressed as a relative risk, and $95 \%$ confidence intervals (CIs) were calculated. Heterogeneity was evaluated using Cochrane's $\mathrm{Tau}^{2}, \mathrm{I}^{2}$, and $\mathrm{Chi}^{2}$ statistics, and high heterogeneity was assumed if the Tau ${ }^{2}$ was greater than zero and either the $I^{2}$ was greater than $30 \%$ or $P$ value was less than 0.10 in the $\mathrm{Chi}^{2}$ test [27]. Subgroup analysis was conducted to identify and explain heterogeneity. Where possible, a funnel plot was used to assess publication bias. We also performed post hoc sensitivity analysis to test the robustness of the overall effect.

\section{Results}

3.1. Study Description. We identified 392 potentially relevant articles. Seven RCTs, including a total of 1387 participants, met our inclusion criteria [16-22] (Figure 1). The characteristics of the 7 trials are summarized in Tables 1 and 2. Of those 7 RCTs, four studies were from Western countries and 


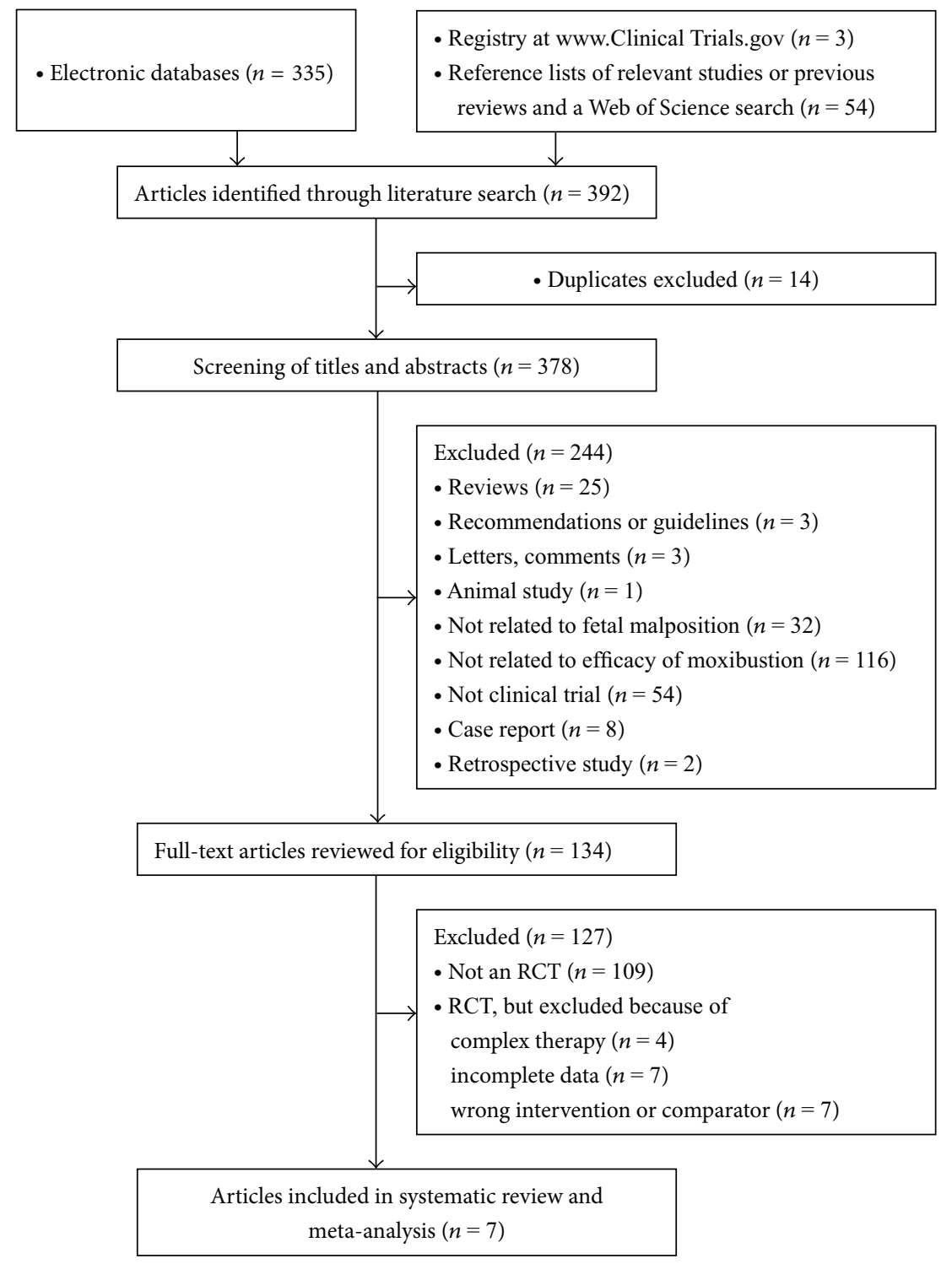

FIGURE 1: Flowchart of study selection.

published in English [18-21], while the other three trials were from China [16, 17, 22], one published in English [17] and two in Chinese [16, 22].

Four trials compared moxibustion therapy with observation $[17,18]$ and usual care $[19,20]$. Two studies compared moxibustion therapy with postural techniques [16, 21], and one study compared moxibustion plus postural technique therapy with postural measures [22].

3.2. Study Quality. The Cochrane risk of bias was presented in Figures 2(a) and 2(b) and Table 3. All seven RCTs reported appropriate sequence generation [16-22]. Six studies conducted concealment of allocation by sealed envelopes [16-21], while one trial did report it [22]. In five studies, moxibustion was either applied at home by participants themselves $[17-19,21]$ or by practitioners in hospital $[16,20]$, while the remaining one study did not state who applied the intervention [22]. In that study, it was not feasible to blind the participant or the therapist. Although the outcome assessor was blinded in only one study [18] and the analyst was blinded to groups in three studies $[16,19,21]$, the review authors deemed that the outcomes and their measurements were not likely to be influenced by lack of blinding. Thus, all studies had a low risk of bias with the Cochrane risk of bias tool at blinding levels. Four studies reported complete followup of all subjects [17-21]. One study stated that 7 women from treatment group and 10 women from control group withdrew from the trial [16]. One trial reported that 1 woman was lost to followup in the control group, and 14 women discontinued treatment in the intervention group [18]. The other one did not provide any information of followup [22]. When it comes to selective reporting bias, the trial protocol was available for two trials $[19,21]$; however, the other five studies failed to provide it $[16-18,20,22]$. Of those five trans, three studies 
TABLE 1: Main characteristics of included RCTs.

\begin{tabular}{|c|c|c|c|c|c|}
\hline Study & Study design & Patient population & Treatment group & Control group & $\begin{array}{l}\text { Outcome } \\
\text { measures }\end{array}$ \\
\hline $\begin{array}{l}\text { Yang et al. } \\
{[16]}\end{array}$ & Parallel 2-arm & 296 participants & $\begin{array}{l}\text { Moxibustion at bilateral BL67; twice } \\
\text { daily, } 30 \text { min each time, } 15 \text { min each } \\
\text { side; } 7 \text { d course }(n=147)\end{array}$ & $\begin{array}{l}\text { Knee-chest therapy; } \\
\text { twice daily, } 15 \text { min each } \\
\text { time }(n=149)\end{array}$ & NCPCT \\
\hline $\begin{array}{l}\text { Cardini and } \\
\text { Weixin [17] }\end{array}$ & Parallel 2-arm & 260 participants & $\begin{array}{l}\text { Moxibustion at bilateral BL67; first } 87 \\
\text { subjects once daily for } 1 \text { week, next } 43 \\
\text { women twice daily for } 7 \mathrm{~d} ; 30 \text { min each } \\
\text { time, } 15 \text { min each side }(n=130)\end{array}$ & $\begin{array}{l}\text { Observation; once or } \\
\text { twice daily for } 30 \text { min } \\
\text { each time, } 15 \text { min each } \\
\text { side }(n=130)\end{array}$ & $\begin{array}{l}\text { (i) NCPDE } \\
\text { (ii) NCPCT } \\
\text { (iii) CS } \\
\text { (iv) UO } \\
\text { (v) AS } \\
\text { (vi) PD } \\
\text { (vii) PRM } \\
\text { (viii) IFD }\end{array}$ \\
\hline $\begin{array}{l}\text { Cardini et al. } \\
{[18]}\end{array}$ & Parallel 2-arm & 123 participants & $\begin{array}{l}\text { Moxibustion at bilateral BL67; twice } \\
\text { daily, } 30 \text { min each time, } 15 \mathrm{~min} \text { each } \\
\text { side for } 1 \text { or } 2 \mathrm{wk}(n=65)\end{array}$ & Observation $(n=58)$ & $\begin{array}{l}\text { (i) NCPCT } \\
\text { (ii) PRM } \\
\text { (iii) PA }\end{array}$ \\
\hline Do et al. [19] & Parallel 2-arm & 20 participants & $\begin{array}{l}\text { Moxibustion at bilateral BL67; twice } \\
\text { daily, } 20 \text { min each time, } 10 \text { min each } \\
\text { side for } 10 \mathrm{~d}(n=10)\end{array}$ & $\begin{array}{l}\text { Usual antenatal care for } \\
\qquad 10 \mathrm{~d}(n=10)\end{array}$ & $\begin{array}{l}\text { (i) NCPDE } \\
\text { (ii) CS } \\
\text { (iii) AS } \\
\text { (iv) PD } \\
\text { (v) PRM }\end{array}$ \\
\hline $\begin{array}{l}\text { Guittier et al. } \\
{[20]}\end{array}$ & Parallel 2-arm & 212 participants & $\begin{array}{l}\text { Moxibustion at bilateral BL67; three } \\
\text { times weekly; } 20 \text { min each time, } 10 \mathrm{~min} \\
\text { each side for } 2 \mathrm{wk}(n=106)\end{array}$ & $\begin{array}{l}\text { Expectant management } \\
\quad \text { care }(n=106)\end{array}$ & $\begin{array}{l}\text { (i) } \mathrm{NCPDE} \\
\text { (ii) } \mathrm{CS} \\
\text { (iii) } \mathrm{AS} \\
\text { (iv) } \mathrm{CBPH}\end{array}$ \\
\hline Vas et al. [21] & Parallel 3-arm & 270 participants & $\begin{array}{l}\text { Moxibustion at BL67; } 20 \text { min each } \\
\text { time, } 2 \mathrm{wk}(n=136)\end{array}$ & $\begin{array}{l}\text { Knee-chest therapy; } \\
20 \text { min each time, } 2 \text { wk } \\
(n=134)\end{array}$ & $\begin{array}{l}\text { (i) NCPDE } \\
\text { (ii) CS } \\
\text { (iii) PD }\end{array}$ \\
\hline Yang [22] & Parallel 2-arm & 206 participants & $\begin{array}{l}\text { Moxibustion at bilateral BL67 + } \\
\text { knee-chest therapy; } 15-20 \mathrm{~min} \text {, twice } \\
\text { daily, } 7 \mathrm{~d} \text { course for } 1 \mathrm{wk}(n=103)\end{array}$ & $\begin{array}{l}\text { Knee-chest therapy, } \\
15-20 \text { min each time, } \\
\text { twice daily, } 7 \text { d course for } \\
1 \mathrm{wk}(n=103)\end{array}$ & NCPCT \\
\hline
\end{tabular}

d: day, wk: week, NCPDE: number of cephalic presentations at delivery (excluding external cephalic version), NCPCT: number of cephalic presentations after cessation of treatment, CS: cesarean section, UO: use of oxytocin, AS: Apgar scores < 7 at 5 min, PD: preterm delivery, PA: placental abruption, PRM: premature rupture of membranes, IFD: intrauterine fetal death, $\mathrm{CBPH}$ : cord blood pH less than 7.1.

included all expected outcomes $[17,18,20]$, while the remaining two failed to state them, so the review authors were unable to determine whether all outcomes were prespecified $[16,22]$. All seven trials conducted sample size calculations [16-21], except for one study that did not report it [22]. Five trans did not report imbalances at randomization, and they appeared free of other sources of bias [17, 19-22]. One study failed to provide sufficient information, so the review author did not determine whether the other bias is present [16]. The other one was interrupted when interim analysis revealed poor compliance and a high number of treatment interruptions [18].

3.3. Outcome Measures. Seven included trials assessed the effect of moxibustion (alone or in association with postural techniques) compared with observation alone or postural measures on cephalic presentation at delivery $[17,19-21]$ and after cessation of treatment [16-18, 22] (Figure 3). Five out of the seven studies involved the other outcomes of safety on the use of oxytocin [17], Apgar scores less than 7 at 5 minutes $[17,19,20]$, cesarean section $[17,19-21]$, preterm delivery $[17,19,21]$, premature rupture of membranes [1719], intrauterine fetal death [17], placental abruption [18], and cord blood $\mathrm{pH}$ less than 7.1 [20] (Figure 4).

Our meta-analysis of four studies [17, 19-21], which included 737 participants, yielded encouraging effects in favor of moxibustion on cephalic presentation at delivery (excluding ECV) (RR 1.29, 95\% CI 1.12 to 1.49 , and $I^{2}=$ 0 ) (Figure 3 ). The same findings applied to the cephalic presentation after cessation of treatment, when moxibustion (alone or in combination with postural techniques) was compared with observation $[17,18]$ or postural techniques $[16,22]\left(\mathrm{RR} 1.36,95 \%\right.$ CI 1.08 to 1.71 , and $\left.I^{2}=80 \%\right)$ (Figure 3 ). A subgroup analysis that excluded two studies with a high risk of bias $[18,22]$ showed significant effect of moxibustion (RR $1.63,95 \%$ CI 1.42 to 1.86 , and $I^{2}=0 \%$ ) (Figure 3 ).

Five trials examined the safety of moxibustion for the correction of non-vertex presentation [17-21] (Figure 4). One study reported significant differences in favor of a reduced use of oxytocin in the treatment group [17] (RR 0.28, 95\% 
TABLE 2: Additional details of the included RCTs.

\begin{tabular}{|c|c|c|c|c|c|c|}
\hline Study & $\begin{array}{l}\text { Location } \\
\text { (country) }\end{array}$ & $\begin{array}{l}\text { Age (mean or } \\
\text { range) }\end{array}$ & Duration & $\begin{array}{c}\text { Gestational } \\
\text { week }\end{array}$ & Inclusion & Exclusion \\
\hline $\begin{array}{l}\text { Yang et al. } \\
{[16]}\end{array}$ & China & $20-36 y$ & $1-2 \mathrm{wk}$ & $30-36$ wk & $\begin{array}{l}\text { Meet the diagnostic } \\
\text { criteria, } 30 \text { to } 34 \mathrm{wk} \text {, } \\
\text { informed consent, } \\
\text { and voluntary } \\
\text { acceptance of the } \\
\text { experiment }\end{array}$ & $\begin{array}{l}\text { Complicated with pregnancy-induced } \\
\text { hypertension, gestational diabetes, } \\
\text { merging genital tumor, contracted } \\
\text { pelvis, polyhydramnios or } \\
\text { oligohydramnios, cord around neck, } \\
\text { and fetal biparietal diameter }>8 \mathrm{~cm} \text {, } \\
\text { before placenta attach to uterine wall }\end{array}$ \\
\hline $\begin{array}{l}\text { Cardini and } \\
\text { Weixin [17] }\end{array}$ & China & $\begin{array}{l}\mathrm{T}: 25.5 \pm 2.5 \mathrm{y} \\
\mathrm{C}: 25.2 \pm 3.0 \mathrm{y}\end{array}$ & $1 \mathrm{wk}$ & 33 wk & $\begin{array}{l}\text { Normal fetal } \\
\text { biometry (biparietal } \\
\text { and abdominal } \\
\text { circumference } \\
\text { between percentiles } \\
10 \text { and } 90 \text { ) }\end{array}$ & $\begin{array}{l}\text { Pelvic anomalies, previous uterine } \\
\text { surgery, pregnancy-related illness, fetal } \\
\text { malformation, twin pregnancy, } \\
\text { fibroma }>4 \mathrm{~cm} \text {, uterine malformation, } \\
\text { risk of premature delivery } \\
\text { (hypercontractility, Bishop } 4 \text { or } \\
\text { greater), and tocolysis during } \\
\text { pregnancy }\end{array}$ \\
\hline $\begin{array}{l}\text { Cardini et al. } \\
{[18]}\end{array}$ & Italy & $\begin{array}{c}\text { T: } 31 \mathrm{y} \\
\mathrm{C}: 26.2 \mathrm{y}\end{array}$ & $1-2 \mathrm{wk}$ & $\begin{array}{l}\text { 32-33 wk plus } \\
3 \mathrm{~d}\end{array}$ & $\begin{array}{l}\text { Normal fetal } \\
\text { biometry }\end{array}$ & $\begin{array}{l}\text { Nonacceptance of randomization, } \\
\text { pelvic anomalies, previous uterine } \\
\text { surgery, fetal malformation, uterine } \\
\text { malformation, fibroma }>4 \mathrm{~cm} \text {, twin } \\
\text { pregnancy, previous or current } \\
\text { tocolysis, and other pregnancy-related } \\
\text { complications }\end{array}$ \\
\hline Do et al. [19] & Australia & $\begin{array}{l}\mathrm{T}: 30.36 \pm 3.13 \mathrm{y} \\
\mathrm{C}: 24.60 \pm 5.23 \mathrm{y}\end{array}$ & $10 \mathrm{~d}$ & $34-36.5 \mathrm{wk}$ & $\begin{array}{l}\text { Women were aged } \\
\text { greater than } 18 \text { years, } \\
\text { at } 34-36.5 \text { wk of } \\
\text { gestation with a } \\
\text { singleton breech } \\
\text { presentation } \\
\text { (confirmed by } \\
\text { ultrasound), and } \\
\text { normal fetal biometry }\end{array}$ & $\begin{array}{l}\text { Twin pregnancy, risk of premature } \\
\text { birth, heart or kidney diseases affecting } \\
\text { the mother, placenta previa, history of } \\
\text { antepartum haemorrhage, intrauterine } \\
\text { growth restriction, hypertensive } \\
\text { disease, isoimmunisation, previous } \\
\text { uterine operations, uterine anomaly, } \\
\text { prelabour rupture of the membranes, } \\
\text { multiple pregnancy, fetal congenital } \\
\text { abnormality, contraindication to } \\
\text { vaginal delivery, and fetal death in } \\
\text { utero }\end{array}$ \\
\hline $\begin{array}{l}\text { Guittier et al. } \\
{[20]}\end{array}$ & Switzerland & $\begin{array}{l}\mathrm{T}: 32.0 \pm 4.3 \mathrm{y} \\
\mathrm{C}: 32.0 \pm 4.2 \mathrm{y}\end{array}$ & $2 \mathrm{wk}$ & $\begin{array}{c}\mathrm{T}: 35 \pm 0.8 \mathrm{wk} \\
\mathrm{C}: 34.8 \pm 0.7 \mathrm{wk}\end{array}$ & $\begin{array}{l}\text { Single fetus in breech } \\
\text { presentation between } \\
34 \text { and } 36 \text { wk of } \\
\text { gestation }\end{array}$ & $\begin{array}{l}\text { Uterine malformation, placenta } \\
\text { praevia, and transverse lie }\end{array}$ \\
\hline Vas et al. [21] & Spain & $\begin{array}{l}\text { T: } 22.6-39.0 y \\
\text { C: } 24.0-38.3 y \\
\text { S: } 24.4-38.0 y\end{array}$ & $2 \mathrm{wk}$ & $33-35$ wk & $\begin{array}{l}\text { Diagnosed by } \\
\text { physical examination } \\
\text { and ultrasound; at } \\
\text { least } 18 \text { years; } \\
33-35 \text { wk of gestation } \\
\text { (confirmed by } \\
\text { ultrasound); normal } \\
\text { fetal biometry and no } \\
\text { prior treatment with } \\
\text { moxibustion to } \\
\text { achieve version of the } \\
\text { fetus }\end{array}$ & $\begin{array}{l}\text { Multiple pregnancy, bone pelvic } \\
\text { defects, previous uterine surgery, fetal } \\
\text { malformation or chromosomal } \\
\text { disorder, uterine malformations, risk } \\
\text { of preterm birth (preterm uterine } \\
\text { contractions and/or initial dilatation } \\
\text { or shortening of the cervix with a score } \\
\text { of } 4 \text { on the Bishop scale), uterine } \\
\text { fibroids }>4 \mathrm{~cm} \text {, tocolytic therapy, and } \\
\text { maternal heart or kidney disease }\end{array}$ \\
\hline Yang [22] & China & $\begin{array}{l}\text { T: } 26-28 y \\
\text { C: } 25-27 y\end{array}$ & $7 \mathrm{~d}$ & $28-32 \mathrm{wk}$ & Not stated & Not stated \\
\hline
\end{tabular}

T: treatment group, C: control group, S: sham group, y: year, wk: week, d: day. 


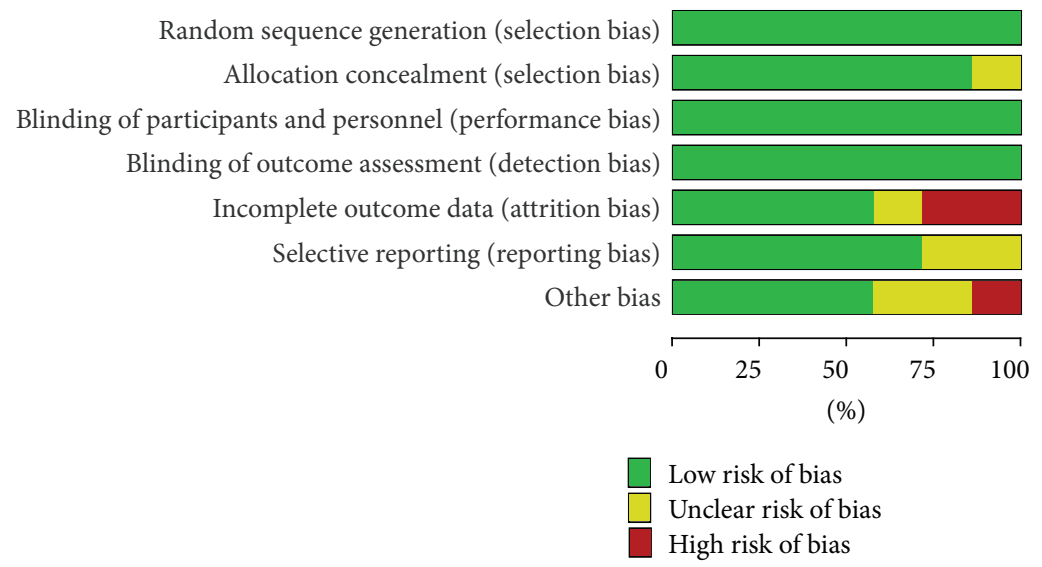

(a)
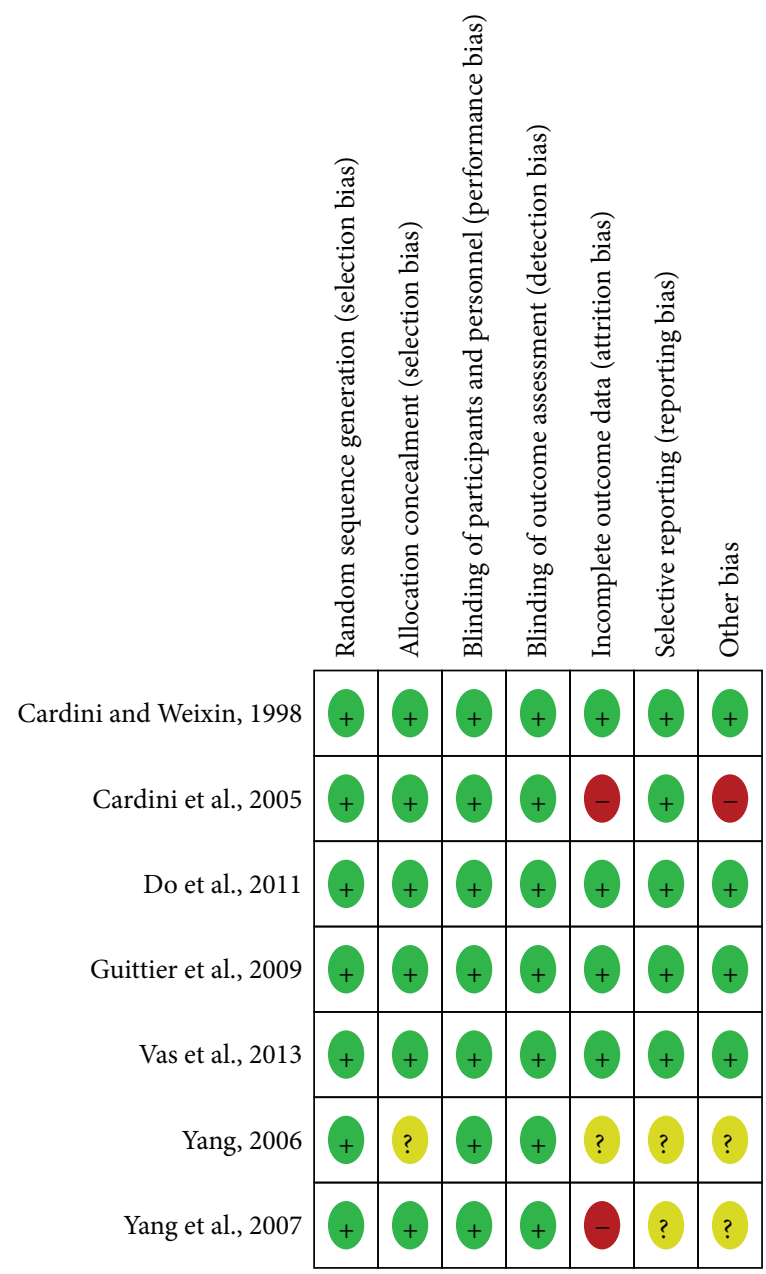

(b)

FIGURE 2: (a) Risk of bias graph: review authors' judgments about each risk of bias item presented as percentages across all included studies. (b) Risk of bias summary: review authors' judgements about each risk of bias item for each included study.

CI 0.13 to 0.60 ) (Figure 4 ). No other statistically significant differences were found in the comparison between moxibustion treatment group and nomoxibustion group on Apgar scores less than 7 at 5 minutes, cesarean section, preterm delivery, premature rupture of membranes, intrauterine fetal death, placental abruption, and cord blood $\mathrm{pH}$ less than 7.1 (Figure 4).

3.4. Adverse Events. Three trials reported the adverse events in the moxibustion group [17-19]: two reported two and four 


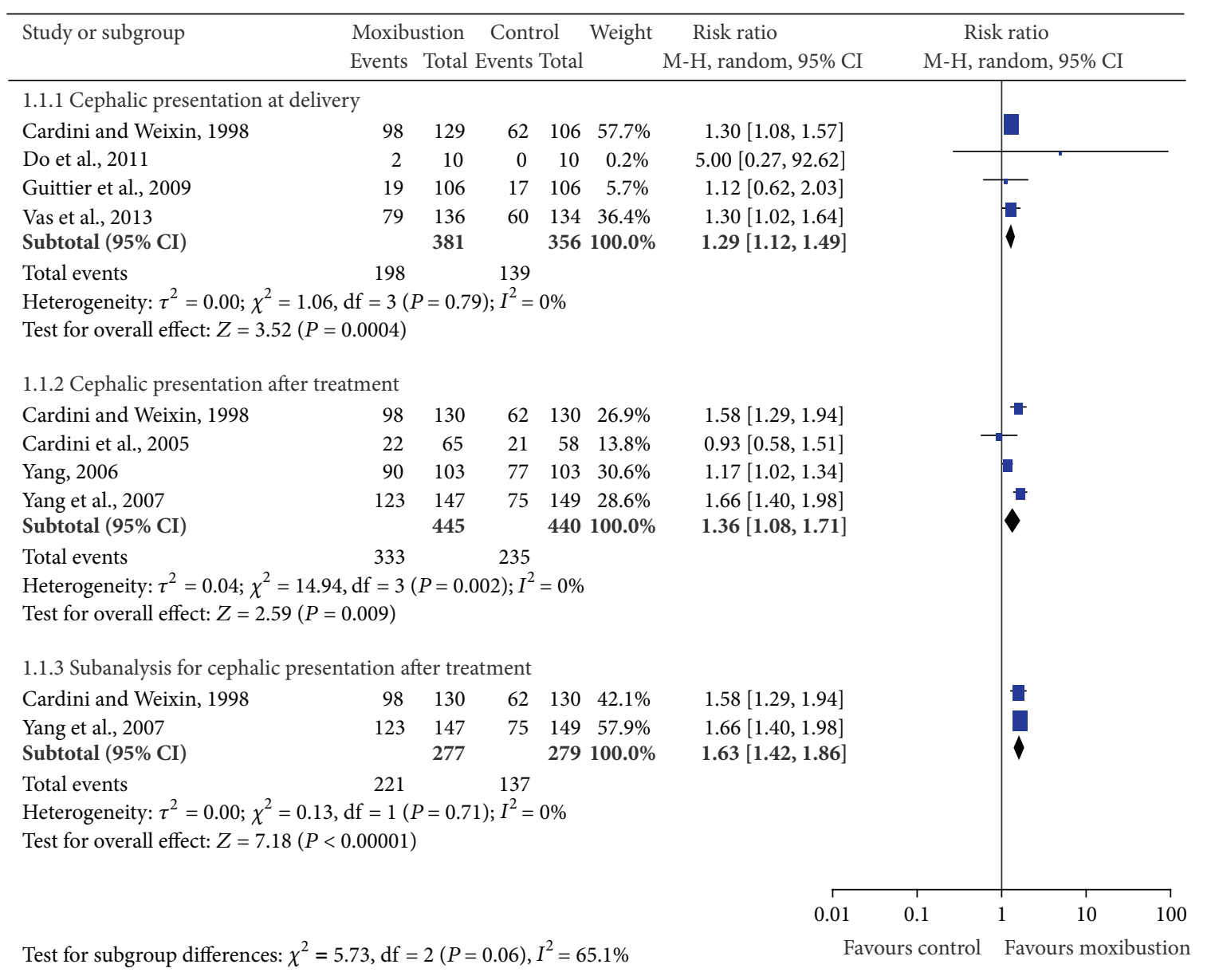

FIGURE 3: Effectiveness of moxibustion for the correction of non-vertex presentation.

cases of premature deliveries at 37 weeks, respectively. Four cases of premature rupture of the membranes after treatment were also reported [17]. Another trial noted two cases of premature deliveries and one case of bleeding at week 37 after ECV due to excessive pressure on the rear of the placenta [18]. The third trial recorded two cases of premature deliveries and three cases of prelabour rupture of the membranes [19].

\section{Discussion}

In this systematic review and meta-analysis, moxibustion at point Zhiyin (BL67) is found to be an effective intervention for correcting non-vertex presentation. With respect to safety, there was no significant difference between moxibustion and control group with outcomes of the use of oxytocin, Apgar scores less than 7 at 5 minutes, cesarean section, preterm delivery, premature rupture of membranes, intrauterine fetal death, placental abruption, and cord blood pH less than 7.1. In case of the use of oxytocin, moxibustion resulted in decreased use of it.

Previous reviews did not include all relevant trials [2326]. For example, all four reviews failed to include the study of Yang and colleagues [16]. Although the newest Cochrane review (from Coyle and colleagues in January 2012, updated to August 2011) was published within the last two years [26], two high-quality RCTs from Do and colleagues in 2011 and Vas and colleagues in 2013 were not included [19, 21]. Moreover, all these reviews included interventions other than moxibustion. For instance, all four studies included trials, which combined with acupuncture therapy [23-26] or even laser intervention [23]. As we know, moxibustion, acupuncture, and lasers are different interventions. Thus, it is difficult to determine what kind of intervention really works for the correction of non-vertex presentation.

We made an effort to identify all relevant trials and included high-quality RCTs. Although one study included in this analysis was of lower quality and resulted in high heterogeneity [22], the subgroup analysis that excluded it still showed a favorable effect of moxibustion for the correction of non-vertex presentation. Our study aims to evaluate the clinical efficacy and safety of moxibustion intervention for the correction of non-vertex presentation, so we only included trials comparing moxibustion with non-moxibustion therapy in participants with non-vertex presentation.

Our review has several limitations. Although great efforts were made to retrieve all trials on the subject, there may 


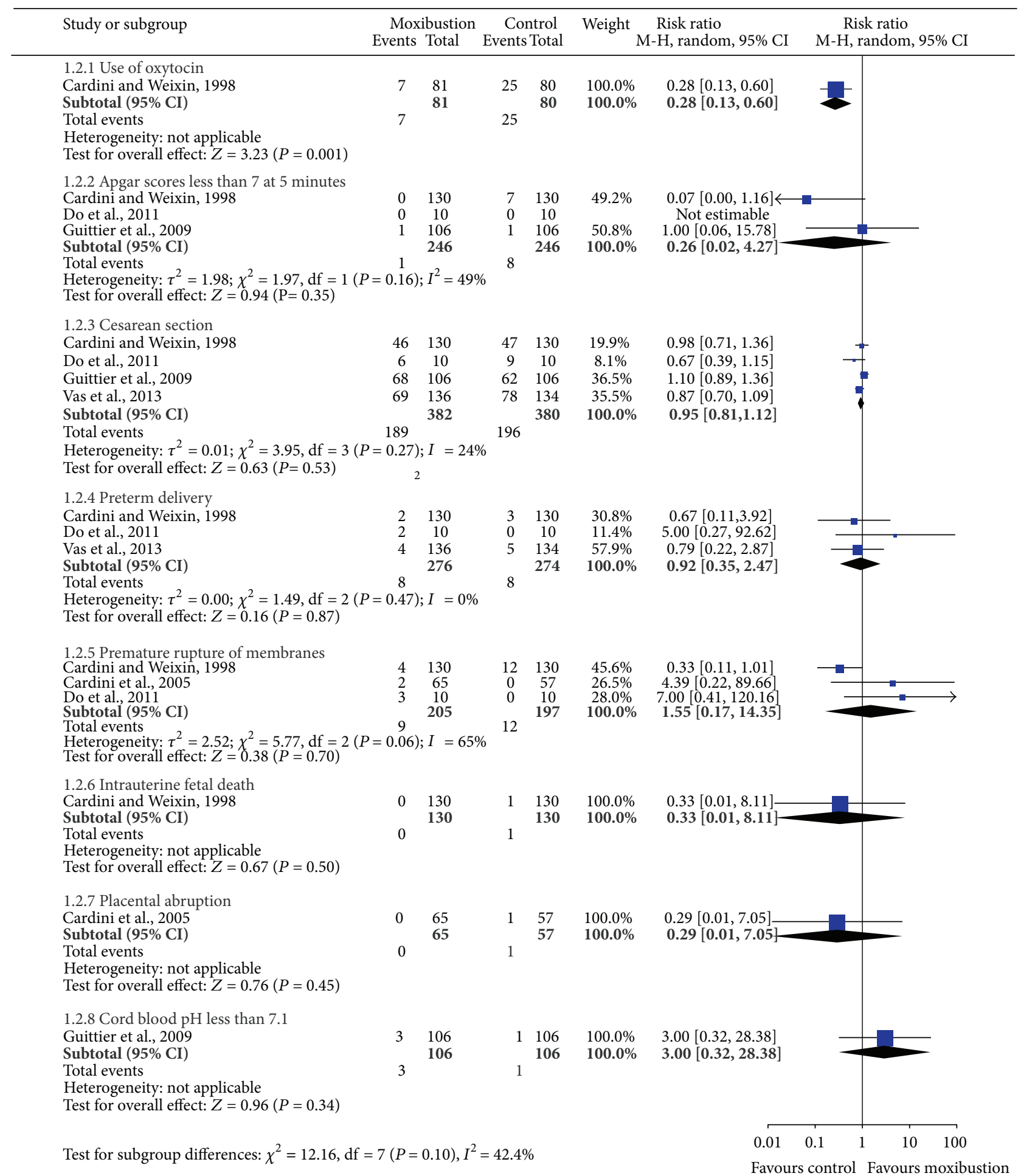

FIGURE 4: Safety of moxibustion for the correction of non-vertex presentation.

be still the possibility of missing studies. In addition, some incomplete information may affect the quality and validity of the results. Finally, a large degree of variability of frequency and duration from three times weekly to once or twice daily might be the possible source of bias.

\section{Conclusion}

The results of our systematic review and meta-analysis showed a positive effect of moxibustion on the correction of non-vertex presentation. In addition, moxibustion might 
TABLE 3: Risk of bias of included RCTs.

\begin{tabular}{|c|c|c|c|c|c|c|c|}
\hline Study & $\begin{array}{l}\text { Random } \\
\text { sequence } \\
\text { generation }\end{array}$ & $\begin{array}{l}\text { Allocation } \\
\text { concealment }\end{array}$ & $\begin{array}{l}\text { Blinding of participants } \\
\text { and personnel }\end{array}$ & $\begin{array}{l}\text { Blinding of } \\
\text { outcome } \\
\text { assessment }\end{array}$ & Incomplete outcome data & $\begin{array}{l}\text { Selective } \\
\text { reporting }\end{array}$ & $\begin{array}{c}\text { Other } \\
\text { bias }\end{array}$ \\
\hline Yang et al. [16] & $\begin{array}{l}\text { Computer } \\
\text { generated }\end{array}$ & $\begin{array}{l}\text { Sealed } \\
\text { envelopes }\end{array}$ & Not stated & $\begin{array}{l}\text { Analyst was } \\
\text { blinded }\end{array}$ & $\begin{array}{l}7 \text { subjects from treatment } \\
\text { group and } 10 \text { subjects from } \\
\text { control group withdrew } \\
\text { from the trial }\end{array}$ & SPUU & IID \\
\hline $\begin{array}{l}\text { Cardini and } \\
\text { Weixin [17] }\end{array}$ & $\begin{array}{l}\text { Computer } \\
\text { generated }\end{array}$ & $\begin{array}{c}\text { Sealed } \\
\text { envelopes }\end{array}$ & $\begin{array}{l}\text { Neither participants nor } \\
\text { practitioner was blinded }\end{array}$ & Not stated & $\begin{array}{c}\text { Complete followup of all } \\
\text { subjects }\end{array}$ & SPUP & $\begin{array}{l}\text { NIR; } \\
\text { SAF }\end{array}$ \\
\hline Cardini et al. [18] & $\begin{array}{l}\text { Computer } \\
\text { generated }\end{array}$ & $\begin{array}{l}\text { Sealed } \\
\text { envelopes }\end{array}$ & $\begin{array}{l}\text { Neither participants nor } \\
\text { practitioner was blinded }\end{array}$ & $\begin{array}{l}\text { Assessor was } \\
\text { blinded }\end{array}$ & $\begin{array}{l}1 \text { subject in control group } \\
\text { was lost to followup; } 14 \\
\text { subjects in intervention } \\
\text { group discontinued } \\
\text { treatment }\end{array}$ & SPUP & TIIA \\
\hline Do et al. [19] & $\begin{array}{l}\text { Computer } \\
\text { generated }\end{array}$ & $\begin{array}{c}\text { Sealed } \\
\text { envelopes }\end{array}$ & Not stated & $\begin{array}{l}\text { Analyst was } \\
\text { blinded }\end{array}$ & $\begin{array}{c}1 \text { subject in control group } \\
\text { was lost to followup, but } \\
\text { less than } 10 \%\end{array}$ & $\begin{array}{l}\text { Study } \\
\text { protocol } \\
\text { available }\end{array}$ & $\begin{array}{l}\text { NIR; } \\
\text { SAF }\end{array}$ \\
\hline Guittier et al. [20] & $\begin{array}{l}\text { Computer } \\
\text { generated }\end{array}$ & $\begin{array}{c}\text { Sealed } \\
\text { envelopes }\end{array}$ & Not stated & Not stated & $\begin{array}{l}\text { Complete followup of all } \\
\text { subjects }\end{array}$ & SPUP & $\begin{array}{l}\text { NIR; } \\
\text { SAF }\end{array}$ \\
\hline Vas et al. [21] & $\begin{array}{l}\text { Computer } \\
\text { generated }\end{array}$ & $\begin{array}{l}\text { Sealed } \\
\text { envelopes }\end{array}$ & $\begin{array}{l}\text { Participants in true and } \\
\text { sham moxibustion } \\
\text { groups were blinded }\end{array}$ & $\begin{array}{l}\text { Analyst was } \\
\text { blinded }\end{array}$ & $\begin{array}{l}\text { Complete followup of all } \\
\text { subjects }\end{array}$ & $\begin{array}{l}\text { Study } \\
\text { protocol } \\
\text { available }\end{array}$ & $\begin{array}{l}\text { NIR; } \\
\text { SAF }\end{array}$ \\
\hline Yang [22] & $\begin{array}{l}\text { Table of random } \\
\text { numbers }\end{array}$ & Not stated & Not stated & Not stated & $\begin{array}{c}\text { Followup of all subjects was } \\
\text { not reported }\end{array}$ & SPUU & IID \\
\hline
\end{tabular}

SPUU: study protocol unavailable; unable to determine whether all outcomes were prespecified, SPUP: study protocol unavailable, but published report includes all expected outcomes, IID: insufficient information to determine whether the other bias is present, NIR: no imbalances at randomization, SAF: study appears free of other sources of bias, TIIA: trial was interrupted when interim analysis revealed poor compliance and a high number of treatment interruptions.

reduce the need for oxytocin. More rigorous high-quality RCTs are still needed to evaluate the efficacy as well as safety of moxibustion for the correction of non-vertex presentation in the future.

\section{Conflict of Interests}

The authors declare that they have no conflict of interests.

\section{Authors' Contribution}

Qin-hong Zhang and Jin-huan Yue contributed equally to this paper.

\section{Acknowledgment}

The study was supported by the Foundation of Heilongjiang University of Traditional Chinese Medicine (nos. 2012RCQ64 and 2012RCL01).

\section{References}

[1] World Health Organization Western Pacific Region, WHO International Standard Terminologies on Traditional Medicine in the Western Pacific Region, World Health Organization Western Pacific, Manila, Philippines, 2007.

[2] M. S. Lee, B.-C. Shin, J.-I. Kim, C.-H. Han, and E. Ernst, "Moxibustion for stroke rehabilitation: systematic review," Stroke, vol. 41, no. 4, pp. 817-820, 2010.
[3] M. S. Lee, T.-Y. Choi, J. W. Kang, B.-J. Lee, and E. Ernst, "Moxibustion for treating pain: a systematic review," American Journal of Chinese Medicine, vol. 38, no. 5, pp. 829-838, 2010.

[4] M. S. Lee, T.-Y. Choi, J.-E. Park, S.-S. Lee, and E. Ernst, "Moxibustion for cancer care: a systematic review and meta-analysis," BMC Cancer, vol. 10, article 130, 2010.

[5] D.-H. Lee, J.-I. Kim, M. S. Lee, T.-Y. Choi, S.-M. Choi, and E. Ernst, "Moxibustion for ulcerative colitis: a systematic review and meta-analysis," BMC Gastroenterology, vol. 10, article 36, 2010.

[6] B. Kim, I. Jang, J. Yeo et al., "Effect of choksamni moxibustion on blood pressure elevation in hypertensive patients: a randomized controlled trial," Korean Oriental Medical Society, vol. 26, pp. 66-73, 2005.

[7] T. Y. Choi, J. Choi, and K. H. Kim, "Moxibustion for the treatment of osteoarthritis: a systematic review and meta-analysis," Rheumatology International, vol. 32, no. 10, pp. 2969-7869, 2012.

[8] M. S. Lee, T.-Y. Choi, J.-E. Park, and E. Ernst, "Effects of moxibustion for constipation treatment: a systematic review of randomized controlled trials," Chinese Medicine, vol. 5, article 28, 2010.

[9] X. Cui, S.-M. Wang, and L.-Q. Wu, "Sixty-eight cases of child chronic cough treated by moxibustion," Journal of Traditional Chinese Medicine, vol. 29, no. 1, pp. 9-10, 2009.

[10] A. Manyande and C. Grabowska, "Factors affecting the success of moxibustion in the management of a breech presentation as a preliminary treatment to external cephalic version," Midwifery, vol. 25, no. 6, pp. 774-780, 2009.

[11] Cooperative Research Group of Moxibustion Version of Jangxi Province, "Studies of version by moxibustion on Zhiyin points," 
in Research on Acupuncture, Moxibustion and Acupuncture Anesthesia, pp. 810-819, Science Press, Beijing, China, 1980.

[12] Cooperative Research Group of Moxibustion Version of Jangxi Province, "Further studies on the clinical effects and the mechanism of version by moxibustion," in Abstracts of the Second National Symposium on Acupuncture, Moxibustion and Acupuncture Anesthesia, pp. 150-151, All China Society of Acupuncture and Moxibustion, Beijing, China, 1984.

[13] F. Cardini, V. Basevi, A. Valentini, and A. Martellato, "Moxibustion and breech presentation: preliminary results," American Journal of Chinese Medicine, vol. 19, no. 2, pp. 105-114, 1991.

[14] S. Budd, "Traditional Chinese medicine in obstetrics," Midwives chronicle, vol. 105, no. 1253, pp. 140-143, 1992.

[15] J.-E. Park, J.-U. Sul, K. Kang, B.-C. Shin, K.-E. Hong, and S.-M. Choi, "The effectiveness of moxibustion for the treatment of functional constipation: a randomized, sham-controlled, patient blinded, pilot clinical trial," BMC Complementary and Alternative Medicine, vol. 11, article 124, 2011.

[16] Y. K. Yang, M. Mao, Y. P. Hu et al., "Effect of moxibustion at zhiyin (BL67) to correct the fetus malposition: multi-center randomized controlled clinical study," Journal of Traditional Chinese Medicine, vol. 48, no. 12, pp. 1097-1110, 2007.

[17] F. Cardini and H. Weixin, "Moxibustion for correction of breech presentation: a randomized controlled trial," Journal of the American Medical Association, vol. 280, no. 18, pp. 1580-1584, 1998.

[18] F. Cardini, P. Lombardo, A. L. Regalia et al., "A randomised controlled trial of moxibustion for breech presentation," An International Journal of Obstetrics and Gynaecology, vol. 112, no. 6, pp. 743-747, 2005.

[19] C. K. Do, C. A. Smith, H. Dahlen, A. Bisits, and V. Schmied, "Moxibustion for cephalic version: a feasibility randomised controlled trial," BMC Complementary and Alternative Medicine, vol. 11, article 81, 2011.

[20] M.-J. Guittier, M. Pichon, H. Dong, O. Irion, and M. Boulvain, "Moxibustion for breech version a randomized controlled trial," Obstetrics and Gynecology, vol. 114, no. 5, pp. 1034-1040, 2009.

[21] J. Vas, J. M. Aranda-Regules, M. Modesto et al., "Using moxibustion in primary healthcare to correct non-vertex presentation: a multicentre randomised controlled trial," Acupuncture in Medicine, vol. 31, no. 1, pp. 31-38, 2013.

[22] F. Q. Yang, "Comparison of knee-chest plus moxibustion on Zhiyin with knee-chest position for breech position," Journal of Sichuan Traditional Chinese Medicine, vol. 24, no. 5, pp. 106-107, 2006.

[23] X. Li, J. Hu, X. Wang, H. Zhang, and J. Liu, "Moxibustion and other acupuncture point stimulation methods to treat breech presentation: a systematic review of clinical trials," Chinese Medicine, vol. 4, article 4, 2009.

[24] M.-L. Liu, L. Lan, Y. Tang, and F.-R. Liang, "Acupuncture and moxibustion for breech presentation: a systematic review," Chinese Journal of Evidence-Based Medicine, vol. 9, no. 8, pp. 840-843, 2009.

[25] J. Vas, J. M. Aranda, B. Nishishinya et al., "Correction of nonvertex presentation with moxibustion: a systematic review and metaanalysis," American Journal of Obstetrics and Gynecology, vol. 201, no. 3, pp. 241-259, 2009.

[26] M. E. Coyle, C. A. Smith, and B. Peat, "Cephalic version by moxibustion for breech presentation," Cochrane Database of Systematic Reviews, vol. 18, no. 2, 2005.
[27] J. P. T. Higgins, D. G. Altman, and J. A. C. Sterne, "Assessing risk of bias in included studies," in Cochrane Handbook For Systematic Reviews of Interventions, J. P. T. Higgins and S. Green, Eds., vol. 8, The Cochrane Collaboration, 2011. 


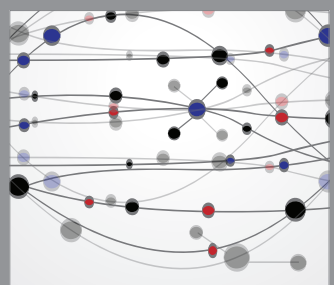

The Scientific World Journal
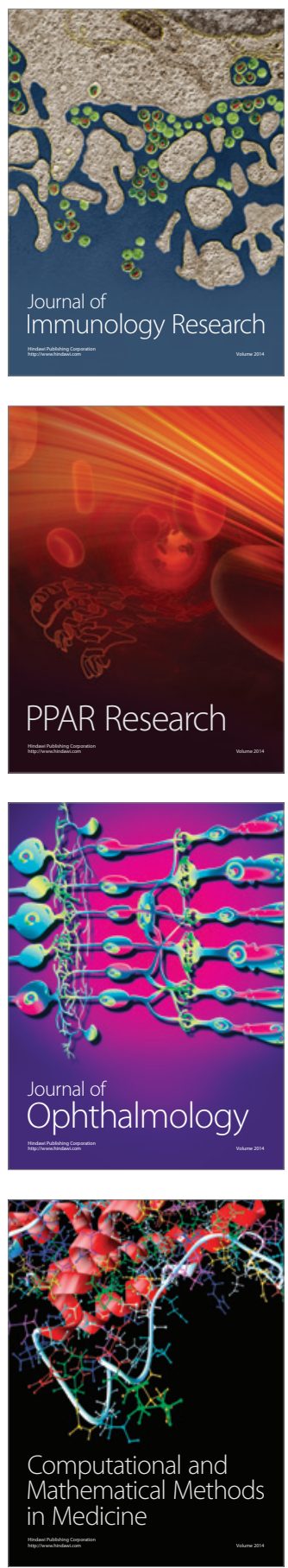

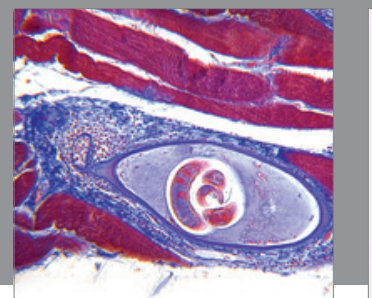

Gastroenterology

Research and Practice
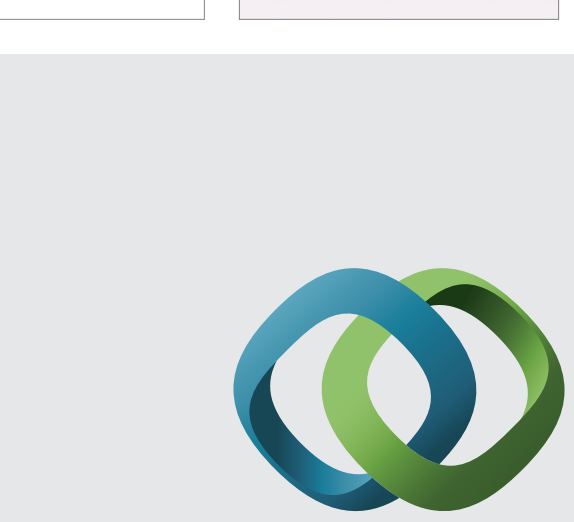

\section{Hindawi}

Submit your manuscripts at

http://www.hindawi.com
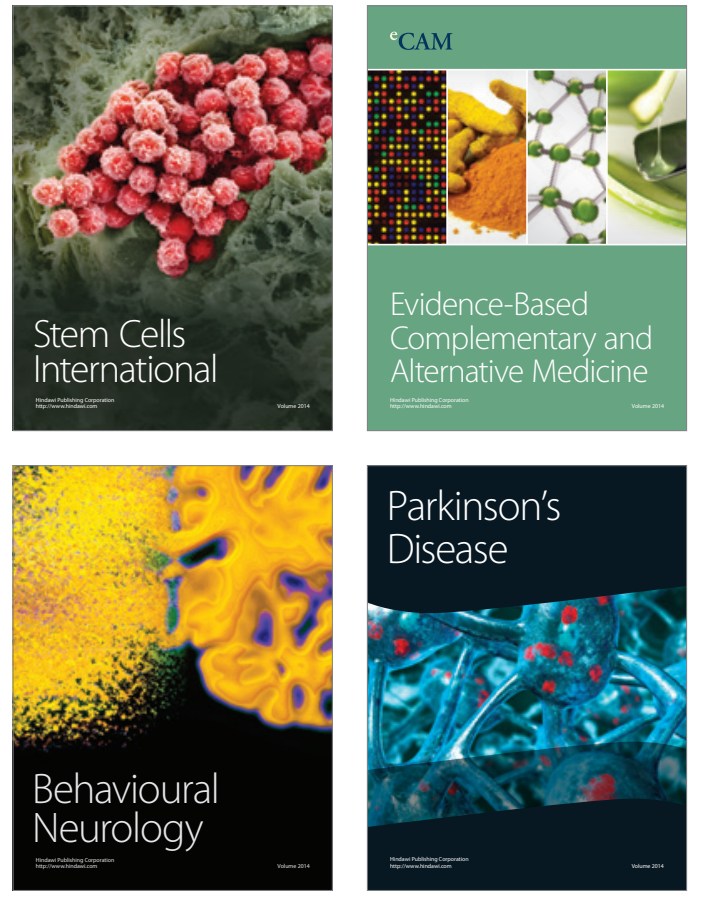
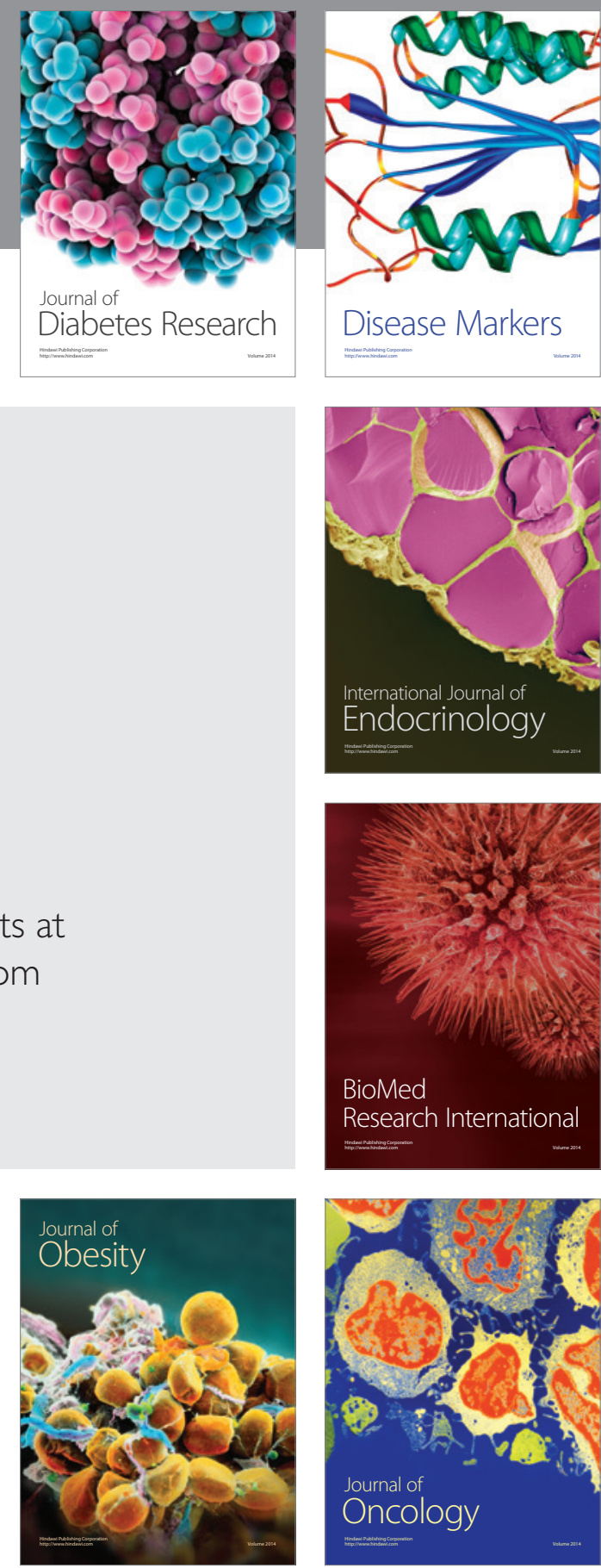

Disease Markers
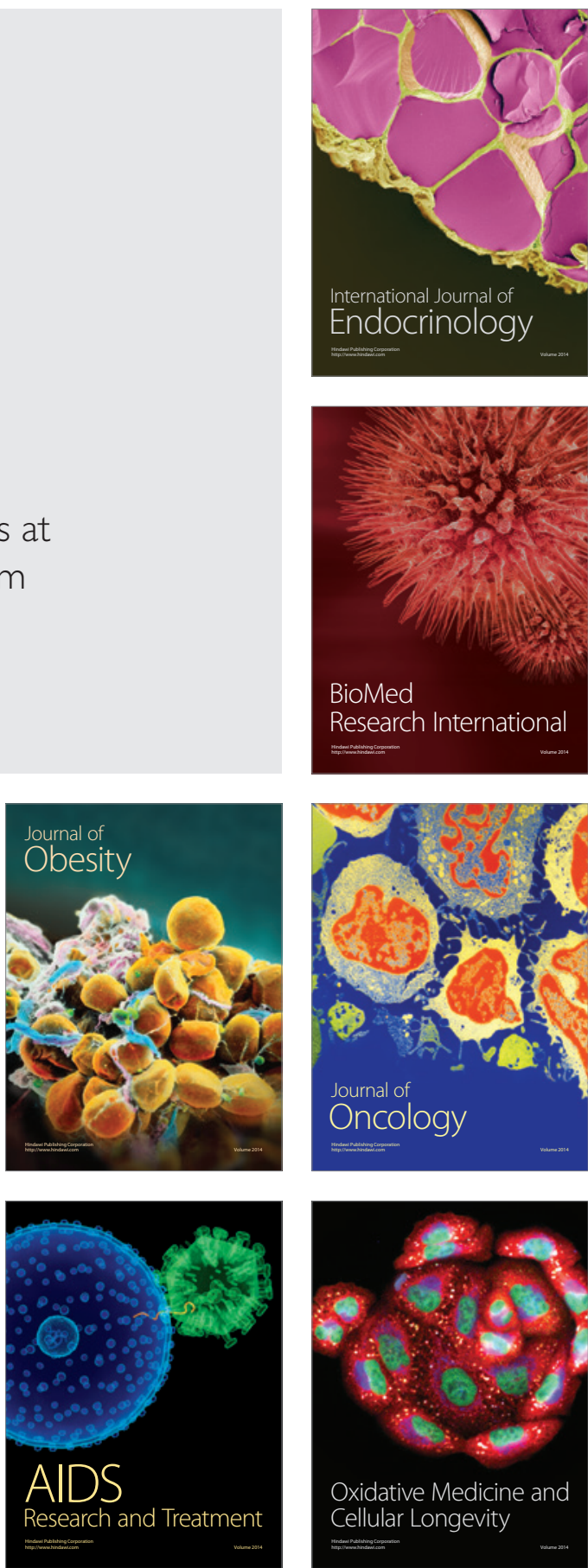